\title{
Vivência da entrevista fenomenológica com usuários de crack: um relato de experiência
}

\section{Phenomenological experience of interview with users of crack: an experience report \\ Experiencia fenomenológica de la entrevista con consumidores de crack: un relato de experiencia}

Fernando José Guedes da Silva ${ }^{1}$ e Claudete Ferreira de Souza Monteiro ${ }^{2}$

${ }^{1}$ Enfermeiro pela Faculdade de Saúde, Ciências Humanas e Tecnológicas do Piauí (NOVAFAPI). Grupo de Estudos sobre Enfermagem, Violência e Saúde Mental. Teresina, Piauí, Brasil.

${ }^{2}$ Doutora em Enfermagem. Professora da Universidade Federal do Piauí e Faculdade de Saúde, Ciências Humanas e Tecnológicas do Piauí (NOVAFAPI). Grupo de Estudos sobre Enfermagem, Violência e Saúde Mental. Teresina, Piauí, Brasil.

Cómo citar este artículo en edición digital: Guedes da Silva Junior, J e Ferreira de Souza Monteiro, C. (2012) Vivência da entrevista fenomenológica com usuários de crack: um relato de experiencia. Cultura de los Cuidados. (Edición digital) 16, 32. Disponible en: <http://dx.doi.org/10.7184/cuid.2012.32.03>

Correspondência: Fernando José Guedes da Silva Júnior: Rua Alcides Freitas, 648, Matinha. CEP: 64003-150. Email: fernandoguedes123@hotmail.com Recibido: 22/11/2011 - Aceptado: 20/02/2012

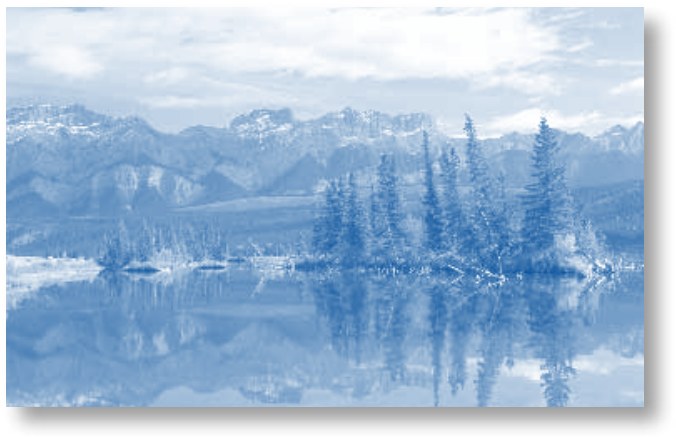

\section{ABSTRACT}

The aidms of this paper is to describe the experience of one of the authors in obtaining reports of crack users using the phenomenological interview. Walk in this process were considered key strategies for approaching the subject of this study, since they supported the familiarity and empathy researcher-subject to this overriding methodological strategy. This manifested itself as a strategy for the seizure of intrinsic meanings about death and dying for userto-be-crack. Obtaining reports reflect the experience of them in the consumption of crack cocaine led to the fact that the absence of an existential sense, one can be and being in the world.

Key words: Illicit drugs. Crack cocaine. Nursing.

\section{RESUMEN}

El propósito de este trabajo es describir la experiencia de uno de los autores en la obtención de informes de los consumidores de crack con la entrevista fenomenológica. Caminar en este proceso se consideraron las principales estrategias para abordar el tema de este estudio, ya que el apoyo de la familiaridad y la empatía investigador-sujeto de esta estrategia metodológica predominante. Esto se manifestó como una estrategia para la toma de los significados intrínsecos sobre la muerte para el usuario-aser-crack. Obtención de informes reflejan la experiencia de ellos en el consumo de cocaína llevó al hecho de que la ausencia de un sentido existencial, se puede estar y ser en el mundo.

Palabras clave: Las drogas ilícitas. Cocaína crack. De enfermería. 


\section{RESUMO}

O objetivo deste artigo é descrever a vivência de um dos autores na obtenção dos relatos de usuários de crack utilizando a entrevista fenomenológica. No trilhar deste processo consideraram-se fundamentais as estratégias de aproximação aos sujeitos deste estudo, uma vez que estas subsidiaram a familiarização e empatia sujeitos-pesquisador imperativas a essa estratégia metodológica. Esta concretizou-se como uma estratégia intrínseca a apreensão dos significados acerca da morte e do morrer para o ser-usuário-de-crack. A obtenção de relatos traduzem a vivência deles no consumo do crack fato que os levou a ausência de um sentido existencial, de poder-ser e de ser-no-mundo.

Palavras-chave: Drogas ilícitas. Cocaína crack. Enfermagem.

\section{CONSIDERAÇÕES INICIAIS}

No Brasil, até o início do século XX, não havia relato sobre abuso e dependência ou preocupações maiores com o crack. No entanto, no período de 1910 a 1920, subleva-se uma grande preocupação com o seu consumo nas grandes cidades: São Paulo e Rio de Janeiro. O país não é um produtor significativo de crack, mas faz parte da rota colombiana do tráfico para os Estados Unidos e Europa, e, mais recentemente, ingressou na conexão nigeriana, vindo a droga a entrar em grandes quantidades no país (Ferreira Filho et al., 2003).

Estima-se que o crack seja consumido por $0,3 \%$ da população mundial e que a maior parte dos usuários, cerca de 70\%, concentram-se nas Américas(5). No Brasil, o uso do crack atinge $0,7 \%$ da população geral, constituindo-se a terceira substância ilícita mais utilizada, perdendo somente para a maconha $(8,8 \%)$ e para os solventes $(6,1 \%)$ (Galduróz et al., 2005; Duailibi; Ribeiro; Laranjeira, 2008; Bernardy; Oliveira, 2010).

A construção teórica do trabalho de campo tem como fundamentação os estudos que mostram como o crack se tornou, nas últimas décadas, um produto de comércio ilícito, cuja produção e distribuição, em escala global, vêm ocasionando desordens sociais, econômicas, políticas, familiar e individual, tornando-se sério problema de saúde pública e grande preocupação para governantes e a sociedade em geral (Ferreira Filho et al., 2003; Galduróz et al., 2005).

Como base metodológica, o trabalho seguiu o método fenomenológico que parte da interrogação ao sujeito; descrição e distinção a partir da compreensão dos próprios sujeitos de estruturas ditas essenciais para construção de unidades de significação e, por fim a hermenêutica (Heidegger, 2009). Na construção desse relato nossa proposta leva o leitor a se voltar ao "como fazer" para interrogar o sujeito. Portanto, o texto pretende oferecer ao iniciante, no fascinante mundo do pesquisar, uma possibilidade de compreensão dessa técnica quando o grupo de entrevistados venha a ser usuários de drogas.

Diante do imaginário popular de que o usuário de crack possa ser uma pessoa de difícil aproximação e que mesmo em tratamento mantém certo distanciamento dos outros, a riqueza dessas entrevistas e desses encontros e o material produzido a partir deles justificam ser relatados como uma experiência enriquecedora tanto para o entrevistador quanto para os entrevistados. Assim, apresentamos como objetivo deste trabalho descrever a vivência de um dos autores na obtenção dos relatos de usuários de crack utilizando a entrevista fenomenológica. 


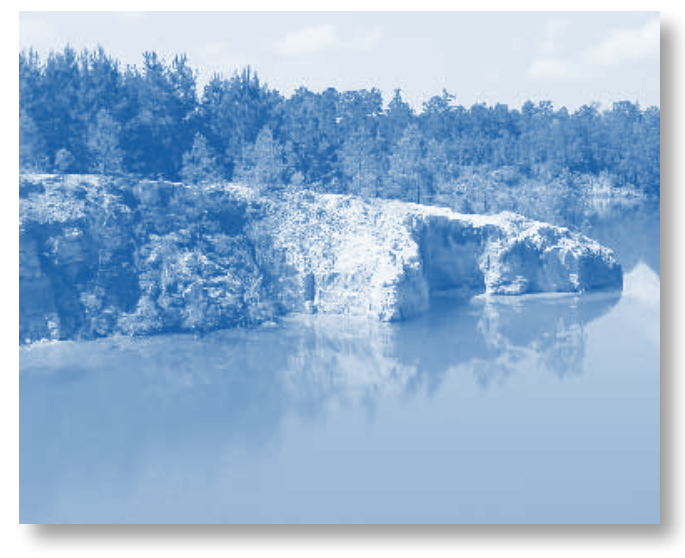

\section{METODOLOGIA}

Ora decidido o cenário do estudo de campo, realizei uma visita inicial na perspectiva de conhecer a estrutura física e, principalmente, aproximar-me do contexto que permeia as relações humanas desses indivíduos no novo ambiente em que se encontravam (usuários-profissionais; usuários-usuários; profissionais-profissionais). Nessa primeira aproximação fui apresentado aos profissionais e na ocasião mostrei o objetivo do estudo, as contribuições e o método a ser seguido. Esse foi um momento que considerei importante pela postura acadêmica, profissional e atenciosa como fui recebido e a relevância que atribuíram ao estudo.

De imediato, fui convidado a participar das terapias de grupo mediadas ora pela enfermeira, ora pelo psicólogo e ora pelo terapeuta ocupacional. Tive, inclusive, a oportunidade de auxiliar na coordenação de algumas dessas sessões e assim pude estabelecer uma familiarização e empatia entre os sujeitos possíveis de participarem do estudo. A relevância do investigador assumir uma atitude de empatia, de diálogo, de liberdade e de cooperação, pois assim favorecerá a compreensão e levará ao alargamento de seu horizonte, que se fundirá com o horizonte do pesquisado (Carvalho; Valle, 2002; Carraro et al., 2011).
Destaco que essa disposição de abertura do pesquisador diante do cenário de estudo seja ao mesmo tempo apaixonante e árdua, pois o desafio de aprender a olhar como se estabelecem essas relações e quais as contribuições do serviço tanto para os sujeitos quanto para o pesquisador necessitem de disciplina e do desejo de abrir-se ao mundo para experenciar algo desprovido de conceitos pré-estabelecidos. Acredito que nessa disposição de abertura em que me coloquei, já lançava mão dos conceitos fenomenológicos heideggeriano de que o ser encontra-se vinculado ao mundo e essa vinculação é sempre com. Essa vinculação é sempre experiência de (Pokladek, 2000).

A aproximação inicial com os usuários de crack me permitiu convidá-los. O livre aceite de uns não foram de outros. Alguns usuários se esgueiravam mansinho pelos cantos numa demonstração clara de evitação. Respeitei todos os modos de se presentificarem nesses momentos.

Para as entrevistas me foi cedida uma sala de consultório, de forma que havia privacidade para os diálogos e para as gravações. Durante o período de obtenção dos depoimentos pude entrevistar 12 usuários de crack, do sexo masculino, maiores de 18 anos e com ensino fundamental completo. Todos possuíam um percurso semelhante quanto a dinâmica do consumo de drogas: iniciaram com uso do loló e lança perfume, seguindo com o consumo da maconha, cocaína e crack.

Destaca-se que esse dados foram produzidos no período de janeiro a março de 2011, para obtenção dos depoimentos com um grupo de usuários de crack que se encontrava em tratamento em um Centro de Atenção Psicossocial para álcool e outras drogas (CAPSad), em Teresina. Os depoimentos obtidos com esse grupo foram analisados no 
Trabalho de Conclusão de Curso da graduação em Enfermagem da Faculdade de Saúde, Ciências Humanas e Tecnológicas do Piauí (Novafapi), intitulado "O significado da morte e o morrer para o ser-usuário-de-crack". Esse trabalho recebeu aprovação do Comitê de Ética em Pesquisa da Novafapi (CAAE $\mathrm{n}^{\circ}$. 0468.0.043.000-10).

\section{RESULTADOS E DISCUSSÃO}

\section{A ENTREVISTA: apreender com o outro}

Iniciou-se as entrevistas a partir dos questionamentos: comente livremente como é ser-usuário-de-crack? Como você relaciona ser-usuário-de-crack com a morte e o morrer? Esses questionamentos me levariam a ouvir relatos de vivência com o crack e como a morte se entrelaça nesse modo de estar e ser-no-mundo.

Os primeiros jovens entrevistados já me fizeram refletir acerca do miserável mundo em que se encontravam. Como se tratava de usuários em tratamento, a dor da separação com o crack é emitida pela fala, pelos gestos, pelo olhar. É algo tão profundo e tão desconcertante para o ouvinte que nos colocam diante de situações jamais imaginadas. Saí desses encontros buscando comigo as diversas razões que impulsionaram esses jovens a adotar o crack como parceiro de vida e de morte. Essa sensação me levou ao afastamento temporário para rever meus conceitos sobre as pessoas que submergem nesse mundo. Considero que somos seres cheios de pré-conceitos e atingir ao que Russel nos orienta para dotar uma suspensão de juízo de valor ante o fenômeno descrito ou de abandono de pressupostos anteriores em relação ao fenômeno é algo intensamente difícil quando realizamos uma entrevista fenomenológica.

Uma vez que o discurso pode ser partilha- do no ser-com, mas para que haja a compreensão é necessário à escuta (Monteiro; Souza, 2005; Moreira; Monteiro, 2009; Batista; Merighi; Freitas, 2011). A escuta atentiva compartilha o ver e o sentir. Nesse compartilhar o pesquisador desenvolve a subjetividade para compreender o procurado. "Existencialmente, o discurso é linguagem porque aquele ente, cuja abertura se articula em significações, possui o modo de ser-lançado-no-mundo, dependente de mundo" (Heidegger, 2009, p. 220). Assim, era preciso ouvir para depois buscar a compreensão desse mundo dos meus depoentes.

Os entrevistados seguiram com relatos semelhantes. Uns dotados de sentimentos de medo, de angústia, outros de paixão pela droga a ponto de expressarem que o crack é vida para eles e que por eles lutam cotidianamente. Em outros relatos o crack é a própria morte.

Essa técnica de obtenção de dados é considerada como um "encontro social", cuja dinâmica necessita primordialmente da empatia e da intersubjetividade, para que ocorra a apreensão mútua de percepções, significados, vivencias. Nessa compreensão pude captar que a instantânea euforia desencadeada pelo consumo do crack reforça e motiva, para a maioria dos indivíduos, o desejo de um novo episódio de consumo subsidiando o estabelecimento de uma relação íntima e quase incoercível entre o dependente e a droga. Embora sintam e conheçam as conseqüências desse uso, eles ultrapassam qualquer obstáculo para irem cada vez mais ao "fundo do poço", numa tentativa desenfreada de sobreviver pela droga.

A entrevista fenomenológica por permitir uma profunda interação com o entrevistado possibilita a este abrir-se tão intensamente que os relatos parecem trazer junto não só o perguntado, mas um mundo que queria ser 
descoberto. No caso dos meus entrevistados, os relatos me levaram a refletir que no fenômeno da dependência de drogas, repousa a privação de valor à vida e a ausência de um verdadeiro e significativo sentido existencial. O usuário de crack não pertence a nada e a ninguém, mas na busca de sua sobrevivência ele morre a cada dia, considerando que a morte é um modo de ser que a presença assume no momento em que é (Heidegger, 2009).

Computo como pontos positivos dessa técnica a minha própria reflexão, como jovem, inserido no grupo de risco para tal consumo, acerca da destruição do "Ser" promovida pela utilização de tal substância. Destaco, ainda, que para efetivação da entrevista fenomenológica o entrevistador deve preparar-se não só tecnicamente, mas, sobretudo, emocionalmente, pois conforme relato nesse texto, experenciamos situações, por vezes, tão dolorosas e que nos rodeiam na cotidianidade e que é preciso preparo do pesquisador para adentrar no mundo vivido dos sujeitos.

\section{CONSIDERAÇÕES FINAIS}

A entrevista fenomenológica concretizou-se como uma estratégia intrínseca a apreensão dos significados acerca da morte e do morrer para o ser-usuário-de-crack, uma vez que esta labora como um "encontro social" mediada por características, tais como: empatia e familiarização são imperativas para o sucesso na obtenção dos relatos.

Considero as abordagens iniciais fundamentais (visita ao CAPSad e participação das terapias de grupo) para a aceitação dos usuários a participar deste estudo de forma voluntária conforme preconiza a Resolução 196/96 do Conselho Nacional de Saúde, bem como para obtenção de relatos que traduzem a vivência deles no consumo do crack.

\section{REFERENNCIAS}

- Baptista, PCP; Merighi, MAB; Freitas, GF. (2011) El estudio de la fenomenología como una vía de acceso a la mejora de los cuidados de enfermería. Cultura de los cuidados, Granada, Jan.-Abr., 15(29): 9-15.

- Bernardy, CCF; Oliveira, MLF. (2010) O papel das relações familiares na iniciação ao uso de dorgas de abuso por jovens institucionalizados. Rev Esc Enferm USP, São Paulo, Mar., 44(1):11-7.

- Carraro, TE; Kempfer, SS; Sebold, LF; Oliveira, MFV; Zeferino, MT; Ramos, DJS et al.(2011) Cuidado de Saúde: uma aproximação teórico-fi losófi ca com a fenomenologia. Cultura de los cuidados, Granada, Jan.-Abr., 15(29):89-96.

- Carvalho, MDB; Valle, ERM. (2002) A pesquisa fenomenológica e a Enfermagem. Acta Scientiarum, Maringá, Abr., 24(3): 843-7.

- Duailibi, LB; Ribeiro, M; Laranjeira, R. (2008) Profile of cocaine and crack users in Brazil. Cad Saúde Pública, São Paulo, Dez., 24(4):545-57.

- Ferreira Filho, OF; Turchib, MD; Laranjeira, R; Castelo, A. (2003) Perfil sociodemográfico e de padrões de uso entre dependentes de cacaína hospitalizados. Rev Saúde Pública, São Paulo, Jul., 37(6): 751-9.

- Galduróz, JC; Noto, AR; Nappo, SA; Carlini, EA. (2005) II Levantamento Nacional sobre o Uso de Drogas Psicotrópicas. Estudo envolvendo 108 maiores cidades do Pais. Centro Brasileiro de Informações sobre Drogas Psicotrópicas (Cebrid), Universidade Federal de São Paulo, São Paulo.

- Heidegger, M. (2009) Ser e Tempo. Vozes, Petrópolis.

- Monteiro, CFS; Souza, IEO. (2007) Vivência da violência conjugal: fatos do cotidiano. Texto Contexto enferm., Florianópolis, Jan.-Mar., 16(1):26-31.

- Moreira, ICCC, Monteiro, CFS. (2009) Vivência da entrevista fenomenológica com prostitutas: relato de experiência. Rev Bras Enferm, Brasília, Jul., 62(4): 789-92.

- Pokladek, DD. (2000) A fenomenologia do cuidar. Fenomenologia e análise do existir (Castro, DSP. org.), Sobraphe, São Paulo pp. 215-23. 